\title{
A percepção da informação e da sua relevância no cenário institucional: sob a perspectiva de gestores e líderes
}

\author{
Perception of information and of its relevance in the institutional setting: from the \\ perspective of managers and leaders
}

Eliane Vieira ${ }^{1}$

\begin{abstract}
Resumo
Considerando o volume e a velocidade da informação que permeia o ambiente organizacional, este artigo tem o objetivo de auxiliar no entendimento e na contextualização dessa informação, por meio da avaliação de lideranças, com o propósito de determinar a percepção da informação e da sua relevância no contexto organizacional. A informação é responsável por contribuir para que a tomada de decisão responda às expectativas da empresa. À luz da teoria proposta por Choo (2003), este artigo reafirma que a informação deve ser processada, visando a reduzir ou evitar a incerteza e apoiar as decisões organizacionais; para isso, a forma como é percebida é vital para que cumpra seu propósito. A metodologia adotada visa a responder às perguntas: "Como a informação é percebida no cenário organizacional?" e "Qual é a relevância da informação?". Trata-se de estudo de caso realizado em uma organização privada, multinacional, do segmento de reflorestamento. Nos resultados, foi possível inferir que os envolvidos possuem uma notável percepção da informação e da sua relevância, embora se tenha observado que, em algumas situações, existe a necessidade de melhorar o fluxo, as ferramentas e a gestão da informação, para que, no contexto organizacional, ela constitua um recurso para decisões efetivas. Identificou-se que a necessidade de informação e sua aquisição, armazenamento, produtos e serviços, uso e disseminação, seguindo o modelo de Choo, realçam a percepção da informação e sua relevância no cenário institucional. A continuidade do estudo sugere a mensuração do impacto e influência da informação e a ampliação da percepção sob a perspectiva de subordinados.
\end{abstract}

Palavras-chave: Percepção da informação. Relevância da informação. Informação no cenário institucional.

\begin{abstract}
Considering the volume and speed of information permeating the organizational environment, this article aims to help understanding and contextualizing this information, by assessing leaderships, in order to determine the perception of information and of its relevance in the organizational context. Information is responsible for contributing so that decisionmaking meets the company's expectations. In the light of the theory proposed by Choo (2003), this article reaffirms that information must be processed, with a view to reducing or avoiding uncertainty and supporting organizational decisions; to do that, the way how it is perceived is crucial to fulfill its purpose. The methodology adopted aims to answer to the questions: "How is information perceived in the organizational setting?" and "What is the relevance of information?". This is a case study carried out in a private, multinational, organization, from the reforestation sector. In the results, we could infer that those who are involved have a remarkable perception of information and of its importance, although it was observed that, in some situations, there is a need to improve information flow, tools, and management, so that, in the
\end{abstract}

Artigo submetido em 14 de junho de 2013 e aceito para publicação em 05 de maio de 2014.

DOI: http://dx.doi.org/10.1590/1679-39519085

1 Mestre em Administração pela Fundação Pedro Leopoldo/FPL; Professora Assistente da Faculdade Arquidiocesana de Curvelo. Endereço: FAC - Faculdade Arquidiocesana de Curvelo, Rua João Pessoa, 88, Centro, CEP 35790-000, Curvelo - MG, Brasil. Email: elianevieira2011@gmail.com 
organizational context, it constitutes a means for effective decisions. We identified that the need for information and its acquisition, storage, products and services, use and dissemination, according to Choo's model, highlight the perception of information and of its relevance in the institutional setting. Subsequently, the study suggests to measure information impact and influence and to broaden perception from the perspective of subordinates.

Keywords: Information perception. Information relevance. Information in the institutional setting.

\section{Introdução}

Na atualidade, denominada Era da Informação e do Conhecimento, o tema informação tem ganhado espaço relevante nas questões relacionadas à gestão das organizações. Por isto, é oportuno definir alguns termos que se inter-relacionam e explicam com mais clareza a relevância da informação no cenário organizacional.

A informação tornou-se, no mundo organizacional, a mercadoria mais valorizada, além de ser a que se expande mais a cada dia. Em uma edição do The New York Times, Wurman (1989) escreveu:

Um dia da semana contém mais informações do que um mortal comum poderia receber durante toda a vida na Inglaterra no século XVII; nos últimos 30 anos produziu-se um volume maior de informações novas do que nos 5.000 anos precedentes. Nesse contexto, pode-se afirmar que "o conhecimento é 'moeda' de nosso tempo, e a velocidade de mudanças é a 'taxa de inflação"”. Quanto mais alta for essa taxa, mais rapidamente essa moeda perde seu valor. (WURMAN, 1989, p. 32).

Diante dessa afirmação, percebe-se que o volume de informações tem crescido continuamente e se tornado, cada vez, mais necessário dentro das empresas. Desde o século XX, a informação tem conquistado relevante espaço no cenário mundial, especialmente após o advento da Internet, quando passou a constituir assunto em diversos setores de discussão. O tema envolve aspectos relativos à economia, política, lazer, educação e, principalmente, negócios. O setor de negócios, mais que outros, atualmente só se efetiva de forma coerente através da informação. Trabalhar a informação de modo a atender todas as pessoas é um desafio constante dos meios de comunicação das empresas; fazer-se entender de forma clara, sem ambiguidades, requer uma avaliação criteriosa dos meios e um profundo conhecimento do público alvo (CALAZANS, 2006).

Ao analisar a informação no contexto das organizações, é importante conceituá-la. Barreto (1996) conceitua o termo informação da seguinte maneira: "estruturas significantes com a competência de gerar conhecimento no indivíduo, em seu grupo ou na sociedade”. (BARRETO, 1996, p.2).

Entende-se que a informação é geradora do conhecimento, elemento fundamental responsável por gerir a tomada de decisão de uma organização. Cada vez mais, o valor da informação tem sido percebido nas organizações, e, conforme Moresi (2000), "o valor da informação é uma função do contexto da organização, da finalidade de utilização, do processo decisório e dos resultados das decisões”. (MORESI, 2000, p.24).

Considerando a circulação de informação de forma geral, abrangente, entre todos os envolvidos e considerando, como informação, todo tipo de notícia, comentário, informação formal e informal, que contribui para a construção de um cenário, este trabalho apresenta a percepção da informação e sua relevância dentro de uma organização, por parte de envolvidos no processo de tomada de decisão.

A circulação da informação formal na organização em estudo acontece de forma sistemática através da elaboração e divulgação do Setor de Comunicação, mas existem outros mecanismos de disseminação da informação que merecem ser estudados, como os programas da Empresa, onde as notícias são transmitidas a um público heterogêneo e por várias lideranças e que requer adequação à realidade da unidade naquele 
tempo e espaço. Ambos são elementos relevantes na percepção da informação e da sua relevância por parte dos envolvidos.

O ponto de partida deste trabalho é a busca pela percepção e a relevância da informação no cenário organizacional, na organização em estudo. Para responder à questão proposta, foram traçados os seguintes objetivos.

\section{Objetivos}

Visando responder à questão proposta, foram definidos os seguintes objetivos:

\section{Objetivo geral}

Verificar a percepção e a relevância da informação no cenário institucional de uma organização privada, multinacional, do setor de reflorestamento.

\section{Objetivos específicos}

- Identificar as demandas de informação existentes na empresa;

- Verificar se a informação é acessível e clara;

- Identificar as ferramentas de comunicação mais usadas na disseminação da informação;

- Analisar se os envolvidos percebem a relevância da informação em seu ambiente profissional.

\section{Referencial Teórico}

\section{A informação no cenário organizacional}

Este estudo requer uma contextualização do cenário organizacional, onde a circulação da informação influencia o processo de tomada de decisão. Para entender como a informação é percebida e considerada no meio organizacional, torna-se necessário conhecer este meio, sua cultura, seu público, seus objetivos, suas transições, suas metas.

Morgan (1996) define as organizações a partir de metáforas que reafirmam a sua complexidade no mundo moderno. Uma das perspectivas adotadas por este autor considera as organizações como cérebros. Nesta abordagem, pode-se analisá-las como cérebros quando se vê a organização como processadora da informação. Para o autor, essa metáfora sugere a informação como elemento norteador do conhecimento que orienta a tomada de decisão. Sem a informação, não é possível "trafegar" no interior de um organismo tão complexo e, para melhor aproveitamento, é salutar a importância da comunicação na produção e na disseminação da informação.

O ambiente organizacional tem sofrido transformações devido às mudanças constantes em suas unidades de negócio. Diante desse cenário, as organizações têm se esforçado no sentido de acompanhar essas mudanças a fim de atualizar as informações para o processo de tomada de decisão (BARBOSA, 2007). 
Mas, para que a informação seja capaz de agregar elementos que auxiliam no processo de tomada de decisão numa organização, é preciso que ela seja adequada ao processo e que a gestão do conhecimento esteja alinhada ao negócio da organização para ser capaz de fomentar a informação de maneira adequada.

Segundo Alvarenga Neto (2002), a gestão do conhecimento é:

O conjunto de atividades voltadas para a promoção do conhecimento organizacional, possibilitando que as organizações e seus colaboradores possam sempre se utilizar das melhores informações e dos melhores conhecimentos disponíveis, com vistas ao alcance dos objetivos organizacionais e maximização da competitividade". (ALVARENGA NETO, 2002, p. 151).

Uma gestão voltada para o conhecimento é aquela capaz de estabelecer uma visão estratégica para o uso da informação e do conhecimento, promover a aquisição, criação, codificação parcial e transferência de conhecimentos tácitos e explícitos, estimular e promover a criatividade, a inovação, a aprendizagem e a educação continuada, além de propiciar um contexto organizacional adequado (ALVARENGA NETO, 2002).

Diante do exposto, sugere-se que as organizações considerem os elementos da gestão do conhecimento para definir o modelo de comunicação a ser adotado. O próximo tópico apresenta o papel da comunicação na disseminação da informação organizacional.

\section{O papel da comunicação na disseminação da informação organizacional}

O processo de comunicação empresarial tem seus objetivos voltados para o atendimento às demandas por informações de todos os públicos da empresa, sejam para aumento da produção, para alteração de procedimentos ou até mesmo para o lazer e a socialização, ambos devem estar alinhados à realidade e ao contexto. As redes de comunicação, tanto as formais quanto as informais, merecem atenção, elas são responsáveis pela disseminação da informação, dos valores organizacionais e da cultura, que dão vida ao dia a dia de uma organização.

A disseminação da informação organizacional depende de um processo de comunicação integrado e alinhado com as diretrizes estratégicas para que se efetive de forma simultânea e abrangente, conciliando a relevância do que se deseja informar com o interesse de quem é informado. Torquato (1986) ressalta o papel da comunicação afirmando que:

Ao assumir funções e características estratégicas, a comunicação se integra a todos os setores e departamentos da organização. Possibilita unificar o conceito da empresa, congregar interesses e evitar sua fragmentação, promovendo, internamente, sinergia negocial e, externamente, comportamentos e atividades favoráveis à organização. (TORQUATO, 1986, p. 68).

A comunicação é responsável por promover a sinergia entre os diversos públicos da organização e sua eficácia está associada ao conhecimento da realidade organizacional. As organizações estão em constante processo de mudança, de inovação pela sobrevivência no mercado, e os padrões de comunicação precisam também acompanhar essa evolução para que a informação seja o elo mais importante entre o interesse da organização e o interesse de seus empregados. 


\section{A informação e sua importância no processo decisório}

De acordo com Choo (1998), o processo decisório é dirigido pela busca de alternativas que sejam boas o bastante, em detrimento da busca pela melhor alternativa existente.

Para Oliveira (1992), a informação auxilia no processo decisório, pois, quando devidamente estruturada, é de crucial importância para a empresa, associa os diversos subsistemas e capacita a empresa a impetrar seus objetivos.

Ao contextualizar a informação no cenário organizacional, percebe-se a sua importância e a sua contribuição para o processo decisório. Segundo Batista (2004), existem dois elementos fundamentais para a tomada de decisões: os canais de informação e as redes de comunicação. Os canais de informação referem-se aos locais de onde se pode retirar os dados que serão usados pelas redes, responsáveis por disseminar e direcionar as informações; portanto, torna-se necessário identificar no meio organizacional quem são canais e quem são as redes e alinhá-los aos objetivos da organização, considerando, como mais importante, o sujeito receptor que deverá interagir com a informação. Neste contexto, consolida-se uma parte importante do papel da informação na tomada de decisão sem se esquecer da relevância da gestão do conhecimento para um processo decisório eficaz. Grande parte do que se convencionou chamar de gestão do conhecimento é na verdade gestão da informação (ALVARENGA NETO, 2002).

Com essa afirmação, o autor concluiu que as organizações que afirmavam ter programas de gestão do conhecimento praticavam, na verdade, a gestão estratégica da informação que, por sua vez, também é um conceito rico em significado.

Ele ainda afirma que:

Apesar de toda a polêmica e controvérsia a respeito do termo "gestão do conhecimento", motivo de discussões, debates, artigos e teses acaloradas, os resultados de sua pesquisa demonstram que a área conhecida como gestão do conhecimento tem surpreendido aqueles que apostaram em um modismo e tem se estabelecido como um consistente paradigma gerencial do século que se inicia. (ALVARENGA NETO, 2002. p. 78).

Davenport (1998) reconhece a dificuldade de se definir, por exemplo, o termo "informação" isoladamente e reitera que as tentativas de fazê-lo pela distinção com dado e conhecimento conjuntamente são nitidamente imprecisas. Sua proposta compreensiva consolida-se pela elaboração de um processo dado-informaçãoconhecimento, apresentado no quadro 1.

Quadro 1

Dados, informação e conhecimento

\begin{tabular}{|c|c|c|}
\hline Dados & Informação & Conhecimento \\
\hline $\begin{array}{l}\text { Simples observações sobre o } \\
\text { estado do mundo: } \\
\text { - facilmente estruturado; } \\
\text { - facilmente obtido por } \\
\text { máquinas; } \\
\text { - frequentemente } \\
\text { - quantificado; } \\
\text { - facilmente transferível. }\end{array}$ & $\begin{array}{l}\text { Dados dotados de relevância e } \\
\text { propósito: } \\
\text { - } \quad \text { requer unidade de análise; } \\
\text { - } \quad \text { exige consenso em relação ao } \\
\text { significado; } \\
\text { - exige necessariamente a } \\
\text { mediação humana. }\end{array}$ & $\begin{array}{l}\text { Informação valiosa da mente } \\
\text { humana. } \\
\text { Inclui reflexão, síntese, contexto. } \\
\text { - de difícil estruturação; } \\
\text { - de difícil captura em máquinas; } \\
\text { - frequentemente tácito; } \\
\text { - de difícil transferência. }\end{array}$ \\
\hline
\end{tabular}

Fonte: Alvarenga Neto (2002). Adaptado de Davenport (1998). 
Davenport e Prusak (1998) acreditam que é possível que se transforme dado em informação pela agregação de valores de diversas maneiras e enumeram métodos importantes, a saber:

- contextualização: sabe-se qual a finalidade dos dados coletados;

- categorização: conhecem-se as unidades de análise ou os componentes essenciais dos dados;

- cálculo: os dados podem ser analisados matemática ou estatisticamente;

- correção: os erros podem ser eliminados dos dados;

- condensação: os dados podem ser resumidos para uma forma mais concisa.

Davenport e Prusak (1998) sugerem ainda que a vantagem do conhecimento é uma vantagem competitiva sustentável e definem o conhecimento como "uma mistura fluida de experiência condensada, valores, informação contextual e insight experimentado, a qual proporciona uma estrutura para a avaliação e incorporação de novas experiências e informações. Ele tem origem e é aplicado na mente dos conhecedores" (DAVENPORT e PRUSAK, 1998, p. 108).

Entende-se com isso que o conhecimento é incorporado por variáveis que permeiam o dia a dia das organizações desde a atuação dos sujeitos até o volume de informações que circulam entre os processos.

De acordo com Choo (1998), as organizações do conhecimento utilizam estrategicamente a informação e o conhecimento para atuar em três arenas distintas, porém imbricadas: construção de sentido, criação de conhecimento e tomada de decisão.

Nesse contexto, o quadro 2 ilustra a condição de aquisição do conhecimento, através da busca da informação, onde se constrói o sentido através da necessidade, busca e uso da informação.

Quadro 2

\section{Processo de construção de sentido}

\begin{tabular}{|c|c|c|}
\hline $\begin{array}{c}\text { Necessidade de } \\
\text { Informação }\end{array}$ & Busca de Informação & Uso da Informação \\
\hline $\begin{array}{c}\text { Quais são as novas tendências da } \\
\text { indústria/setor? }\end{array}$ & $\begin{array}{c}\text { Escaneamento ambiental. } \\
\text { Sistema de informações. }\end{array}$ & $\begin{array}{c}\text { Redução de incerteza e } \\
\text { Quais são as competências } \\
\text { essenciais dos concorrentes? } \\
\text { O que os nossos clientes } \\
\text { valorizam? }\end{array}$ \\
$\begin{array}{c}\text { Pesquisas. } \\
\text { Construção de conhecimento } \\
\text { compartilhado. }\end{array}$ \\
\hline
\end{tabular}

Fonte: Alvarenga Neto (2002). Adaptado de CHOO (1998).

Já na figura 1, o autor apresenta os pontos que convergem para as ações da organização e que fomentam a criação do conhecimento. Observa-se também que a figura sugere uma análise cíclica dos elementos que, integrados, norteiam a tomada de decisão e reforça, sobretudo, a importância da informação nesse processo. 
Figura 1

\section{Criação do conhecimento}

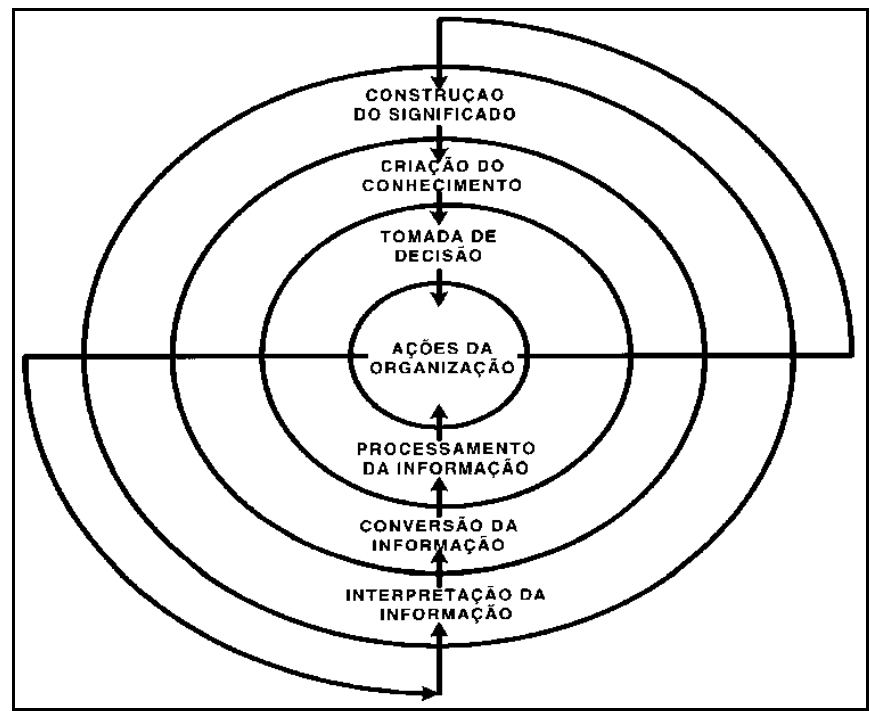

Fonte: Choo (2003).

Com essa análise, é possível inferir que tanto o processo de construção do sentido quanto a criação do conhecimento têm como eixo estruturante a informação.

O modelo processual de gerenciamento da informação, sugerido por Choo (2003), será descrito a seguir.

\section{Modelo de gerenciamento da informação}

O modelo de gerenciamento da informação adotado para a realização deste trabalho é o modelo proposto por Choo (2003), baseado na proposta de Davenport (1998), que trazia as seguintes etapas: identificação de necessidades e exigências de informação, coleta e aquisição de informação, categorização e armazenamento de informação, compactação e formatação da informação, disseminação e distribuição da informação e análise e uso da informação.

A evolução dos processos exigiu uma adequação nas etapas do modelo de gerenciamento da informação, que foram definidas por Choo (2003) da seguinte forma:

a) a identificação das necessidades de informação;

b) a aquisição da informação;

c) a organização e armazenamento da informação;

d) o desenvolvimento de produtos e serviços de informação;

e) a distribuição da informação;

f) o uso da informação. 
Os processos de gerenciamento da informação propostos pelo autor estão descritos na figura 2, que segue:

Figura 2

\section{Ciclos da gestão da informação}

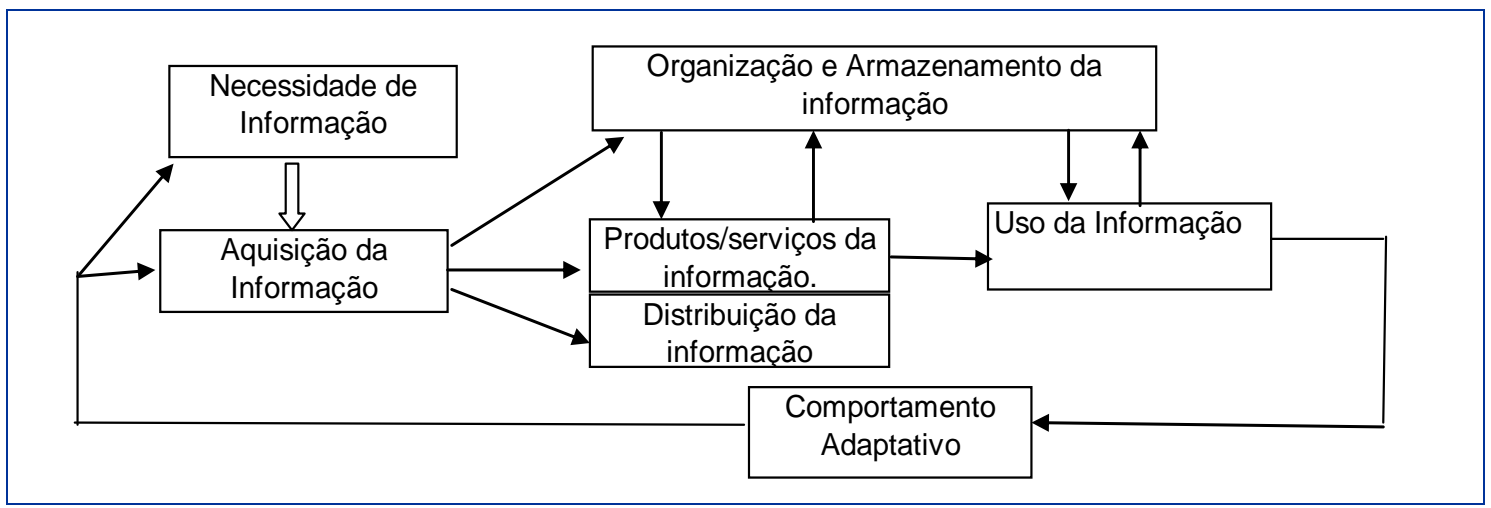

Fonte: Choo (2003). Adaptado pela autora.

O ponto de partida do ciclo de gestão da informação defendido por Choo (2003) é o comportamento adaptativo, através do qual surgem as demandas de informação e viabilização de todo o processo de gerenciamento da informação, que será apresentado e contextualizado a seguir.

\section{Necessidade de informação}

A identificação da necessidade de informação torna-se necessária num ambiente onde circulam informações e pessoas que convivem com realidades distintas e que necessitam de informações para entenderem o seu papel dentro das organizações. Para Choo (2006), "as necessidades de informação são condicionais, dinâmicas e multifacetadas, e uma especificação completa só é possível dentro de uma rica representação do ambiente total em que a informação é usada". (CHOO 2006, p. 406).

Apesar de muitas pessoas nunca pararem para identificar as suas necessidades de informação, é sabido que elas atendem à necessidade do saber, de ter conhecimento e às necessidades da ação, como usar a informação de modo a desenvolver a atividade. Para identificar a necessidade de informação, algumas perguntas são necessárias, as quais, de acordo com Le Coadic (2004), estão descritas a seguir:
A - Quem necessita da informação?
B - Que tipo de informação?
$\mathrm{C}$ - Para qual grupo de pessoas?
$\mathrm{D}$ - Por que precisam dela?
E - Quem decide quanto à necessidade?
F - Quem seleciona?
$\mathrm{G}$ - Que uso é dado ao que é fornecido? 
H - Quais são as consequências ou resultados do uso para o indivíduo, o grupo, a organização, etc.?

Essas perguntas são necessárias para identificar a necessidade da informação e entender como ela se processa dentro das organizações.

\section{Aquisição da informação}

Para Choo (2006), vários critérios podem influenciar a seleção e o uso da informação. Pesquisas mostram que o acesso é mais importante que a qualidade, muitos preferem fontes locais mesmo que não sejam confiáveis, porque priorizam o acesso. A aquisição da informação, segundo o autor, deve atender a duas demandas: grande amplitude para atender às necessidades e manter uma seleção capaz de atender às limitações da capacidade de atenção e cognitiva.

Essa afirmação de Choo (2006) ressalta a importância do acesso à informação para que o processo de aquisição seja cumprido, mas chama atenção também para fatores que podem, se não percebidos, comprometer a aquisição, como a seleção, por exemplo, que aproveita ou descarta a informação. Diariamente, recebemos um volume grande de informação, conforme citado por Wurman (1989), no início deste trabalho. Diante desse contexto, Choo (2006) afirma que "uma forma de tratar a variedade de informações é envolver o máximo de pessoas, possível, na captura de informações, criando uma rede de coleta de informações". (CHOO, 2006, p. 414).

\section{Organização e armazenamento da informação}

A informação é a memória da organização, por isso o processo de organização e armazenamento é relevante; ele contribui para entender os processos, o passado, a evolução e o futuro de uma organização. Segundo Choo (2006), "a maneira como a informação é armazenada reflete como a organização percebe e representa o seu ambiente" (CHOO, 2006, p. 417).

A informação deve ser organizada e armazenada de forma que possa ser acessada e resgatada sempre que necessário, e essa demanda é função da área de tecnologia que aponta as melhores mídias e formas de se armazenar e de conservar a informação e a memória da instituição.

\section{Produtos e serviços de informação}

Para Choo (2006), o objetivo, ao desenvolver produtos e serviços de informação, deve atender não apenas à necessidade de informação do usuário, mas atender à sua necessidade de informação para o desenvolvimento de suas atividades. A informação deve contribuir para agregar valor à atividade e ao desempenho dos usuários.

\section{Distribuição da informação}

A distribuição da informação de forma ampla promove maior aprendizado organizacional, auxilia no processo de recuperação de informações relevantes e permite a criação de novas informações ou conhecimentos pela associação de informação de áreas diversas, conforme afirma Choo (2006), "a entrega da informação deve ser feita por meios que estejam de acordo com os hábitos e preferências dos usuários de acordo com o seguinte princípio 'a informação certa para a pessoa certa, no formato local e horas certos"'. (CHOO, 2006, p. 414). 
A afirmação do autor sugere que a distribuição da informação não deve acontecer de forma aleatória, mas deve estar em consonância com a rotina, os interesses e a realidade dos envolvidos nas organizações. A distribuição da informação de forma calculada contribui para a codificação da mensagem e, através da interação do receptor, favorece o surgimento de novas informações.

\section{Uso da informação}

O uso da informação pelos indivíduos se processa quando ele seleciona a informação num grupo maior de mensagens que recebe, por isso é importante que a distribuição seja feita de forma criteriosa, considerando a pessoa que a recebe, o momento em que a recebe e a forma como a recebe. "O uso da informação envolve a seleção e o processamento da informação de modo a responder uma pergunta, resolver um problema, tomar uma decisão, negociar uma posição ou entender uma situação" (CHOO, 2006, p. 116).

Para o autor, o processo ocorre de forma interativa e municia o indivíduo de informações para atuar na tomada de decisão. O uso da informação é definido com base na experiência, vivência e educação de cada indivíduo. "A gestão da informação deve considerar o contexto social do uso da informação, uma vez que ela ganha significado e propósito pelo compartilhamento mental e afetivo" (CHOO, 2006, p. 416).

O modelo proposto por Davenport (1998) dará sustentação ao modelo de Choo (2003) adotado como modelo de análise do processo de gerenciamento da informação na Empresa em estudo.

\section{Metodologia}

A metodologia adotada para a realização deste trabalho considerou o objetivo que se pretendeu alcançar com a pesquisa e buscou em autores como Gil (2002), Vergara (2002) e Bardin (2002) subsídios e orientações para a realização da pesquisa.

\section{Característica da pesquisa}

Para identificar a percepção da informação e sua relevância no cenário institucional estudado, foi necessário analisar como os membros da organização lidam com a informação no desenvolvimento de suas atividades. Para isso, foi realizada uma pesquisa de campo que, segundo Vergara (2002), "é a investigação de um tema realizada no local onde ocorreu o evento ou que tenha elementos para explicá-lo. Pode-se realizar entrevistas, aplicar questionário e realizar observações". (VERGARA, 2002, p. 12).

A presente pesquisa, quanto à abordagem, caracteriza-se como qualiquantitativa. No caso, é quantitativa porque os questionários utilizados foram compostos de questões objetivas, geralmente de múltipla escolha e foram submetidos a uma análise estatística. A pesquisa é também qualitativa, porque se pretendeu verificar a qualidade das informações obtidas, mediante análise das características específicas e mesmo subjetivas.

Quanto aos fins, o estudo teve caráter descritivo onde se propôs descrever a realidade com o objetivo de apresentar sugestões que favoreçam a percepção da informação e de sua relevância no cenário institucional (VERGARA, 2002).

O meio que melhor atende a essa proposta é o estudo de caso que, para Gil (2002), "é um estudo profundo e exaustivo de um ou poucos objetos de maneira que permita seu amplo e detalhado conhecimento. Amplamente utilizada nas ciências sociais". (Gil, 2002, p. 27). 
A pesquisa apresenta limitações no que se refere ao volume de respostas obtidas, em função da dispersão de suas unidades, mas a amostragem possibilita inferir os resultados comuns, considerando que o grupo de entrevistados, que responderam à pesquisa, representam todas as unidades da organização em estudo e possuem representação significativa nos processos.

Desse modo, apesar de o estudo de caso ser um recurso limitado quanto à possibilidade de generalização, é aquele que melhor permite caracterizar o quadro abordado.

\section{Unidade de análise e sujeitos da pesquisa/universo e amostra}

A pesquisa realizada tomou como unidade de análise uma empresa multinacional, privada, do segmento de reflorestamento. Essa empresa foi escolhida devido à característica de seu negócio. A atividade florestal caracteriza-se pela dispersão das áreas de plantio, espalhadas por diversos municípios e um escritório central de onde partem todas as decisões que orientam as atividades de campo. A dispersão da organização exige que a informação permeie todas as áreas para que as decisões organizacionais sejam incorporadas por todos os envolvidos. Nesse contexto a percepção da informação e sua relevância, elementos de estudo deste trabalho, devem ser criteriosamente avaliados para que, de fato, contribuam para que o ciclo da gestão da informação, sugerido por Choo (2003), consolide-se. É essa complexidade o principal elemento que motivou a realização desse estudo.

O universo da pesquisa foi constituído pelas pessoas que exercem cargo de liderança na empresa estudada, ou seja, gerentes, supervisores, analistas e controladores de produção. O questionário foi encaminhado às 50 pessoas que compõem este universo; entretanto, apenas 37 delas responderam, constituindo uma amostra representativa da população estudada; trata-se de amostra não probabilística, por acessibilidade e por tipicidade (VERGARA, 2002).

No tocante à análise qualitativa da pesquisa, foram selecionadas 3 lideranças, representantes das três principais operações da empresa, por serem consideradas as que melhor representavam o grupo estudado. Esses sujeitos selecionados lidam diariamente com a informação e são porta-vozes entre os demais empregados. As entrevistas foram submetidas à análise de conteúdo qualitativa.

\section{Coleta de dados}

A coleta de dados foi realizada através de um questionário e uma entrevista semiestruturados. O questionário foi composto de questões objetivas e teve 4 segmentos: o primeiro esteve voltado para a identificação dos respondentes; o segundo se referiu aos processos da empresa; o terceiro tratou das informações sobre os veículos de comunicação utilizados na disseminação da informação e o quarto foi referente ao armazenamento da informação. O questionário foi aplicado ao longo de dois meses em cada uma das unidades da empresa. Foi elaborado utilizando como base a realidade informacional e a dinâmica da organização, no tocante à circulação da informação e às formas como se desenham as suas relações e decisões institucionais. A entrevista semiestruturada foi realizada com as lideranças regionais.

\section{Estratégia de análise de dados}

O material coletado pelos questionários foi analisado estatisticamente para melhor compreensão do processo de informação. Além disso, as entrevistas feitas com as lideranças mencionadas acima foram submetidas à análise de conteúdo, servindo para clarificar aspectos levantados nas respostas aos questionários. A análise de conteúdo constitui: 
Um conjunto de técnicas de análise das comunicações, visando obter, por procedimentos sistemáticos e objetivos, a descrição do conteúdo das mensagens, indicadores (quantitativos ou não) que permitam a inferência de conhecimentos relativos às condições de produção/recepção (variáveis inferidas) destas mensagens. (BARDIN, 2002, p. 42).

Considerando tanto o objetivo geral quanto os objetivos específicos que foram definidos, a análise dos dados buscou analisá-los conforme modelo de gerenciamento de informação sugerido, à luz da teoria de Choo (2003), e apresenta as conclusões que se seguem.

\section{Análise da Pesquisa}

Os aspectos mais importantes da pesquisa são relatados a seguir e foram analisados à luz do modelo de gerenciamento da informação proposto por Choo (2003).

A - Necessidade de informação: a circulação de informação na empresa é considerada importante por 100\% dos entrevistados, o que reafirma a necessidade de informação para todos os públicos. As lideranças da empresa afirmam que disseminam as informações sobre os processos entre os seus subordinados, com ênfase nos processos produtivos, embora o administrativo também seja retratado de forma representativa. Com esse resultado, é possível considerar que a necessidade é identificada como aspecto facilitador do desenvolvimento das atividades consolidando a teoria de que "as necessidades de informação são condicionais, dinâmicas e multifacetadas, e uma especificação completa só é possível dentro de uma rica representação do ambiente total em que a informação é usada". (CHOO 2006, p.406).

\section{Gráfico 1}

Importância atribuída à informação pelas lideranças

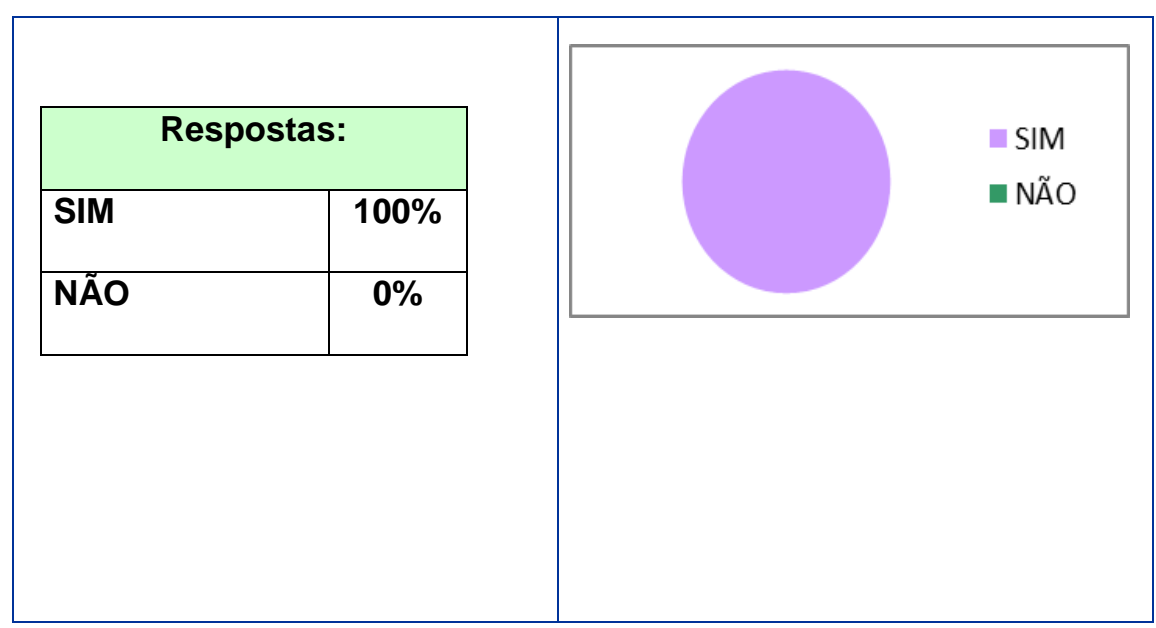

Fonte: Dados da pesquisa. 


\section{Gráfico 2}

Processos mais informados às lideranças no dia a dia de sua atividade na empresa

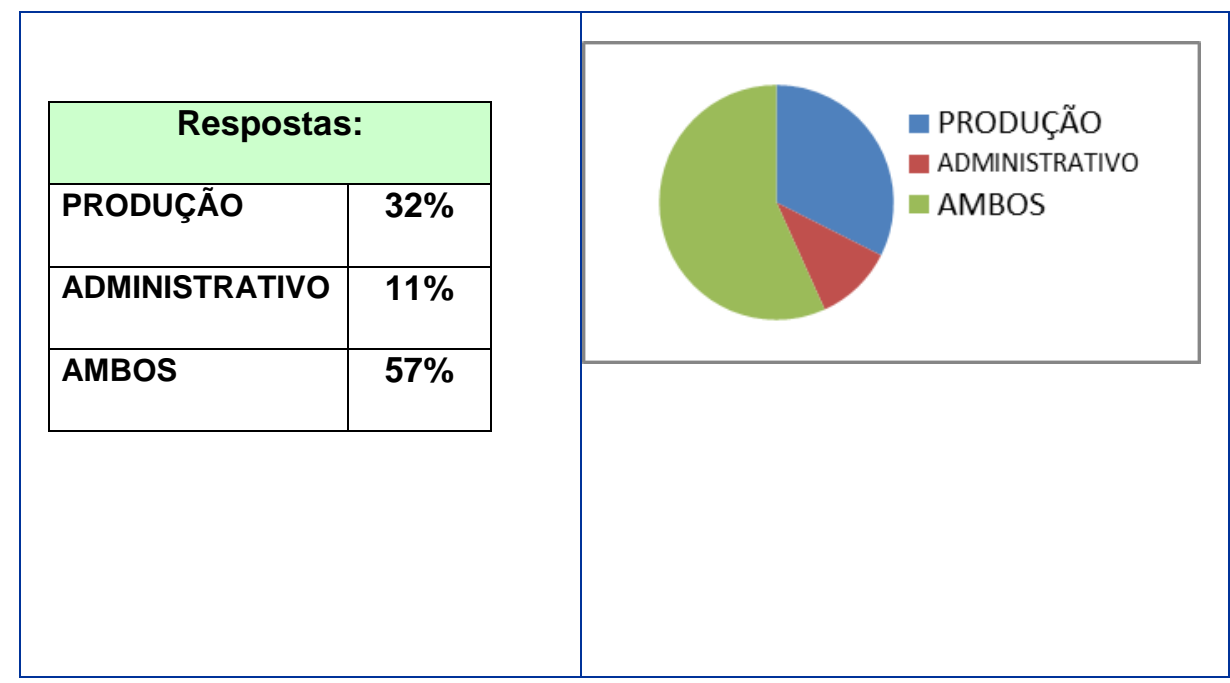

Fonte: Dados da pesquisa.

\section{Gráfico 3}

Disseminação da informação sobre os processos da empresa entre os subordinados

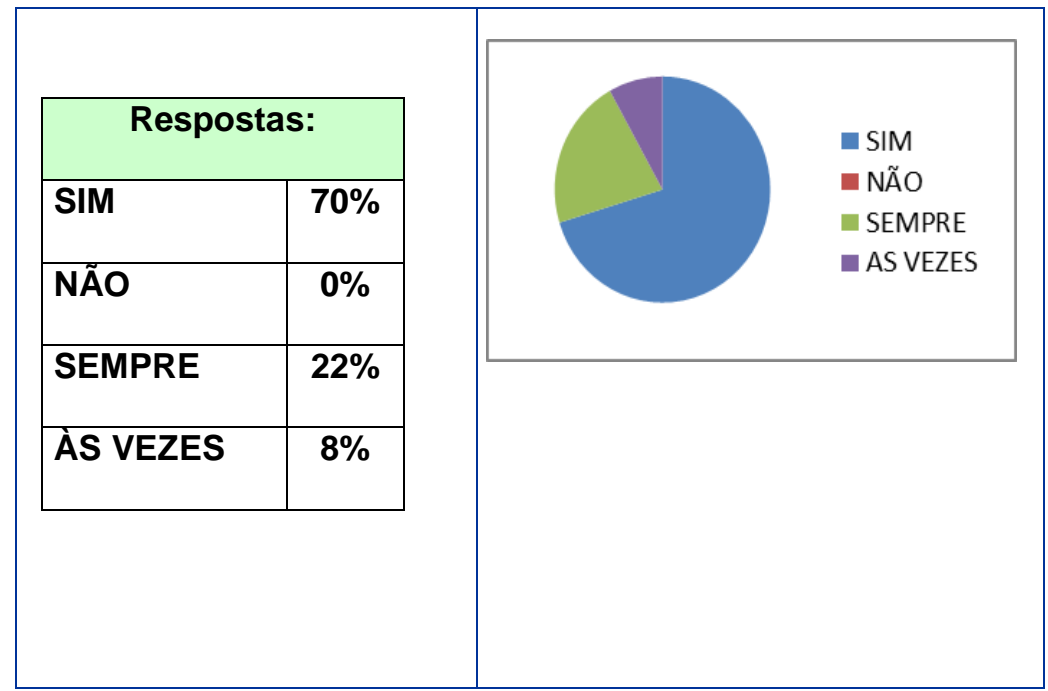

Fonte: Dados da pesquisa.

\section{B - Aquisição da informação}

"Uma forma de tratar a variedade de informações é envolver o máximo de pessoas, possível, na captura de informações, criando uma rede de coleta de informações". (CHOO, 2006, p. 414).

O resultado da pesquisa mostra que $81 \%$ dos entrevistados consideram que a aquisição da informação auxilia nas atividades de suas áreas, no dia a dia. Há uma nítida percepção dos envolvidos com relação à importância e relevância da informação no ambiente institucional, possibilitando, dessa forma, o envolvimento de mais pessoas na criação da rede de coleta de informações, conforme sugerido por Choo (2006). 


\section{Gráfico 4}

Ajuda fornecida aos subordinados nas atividades do dia a dia

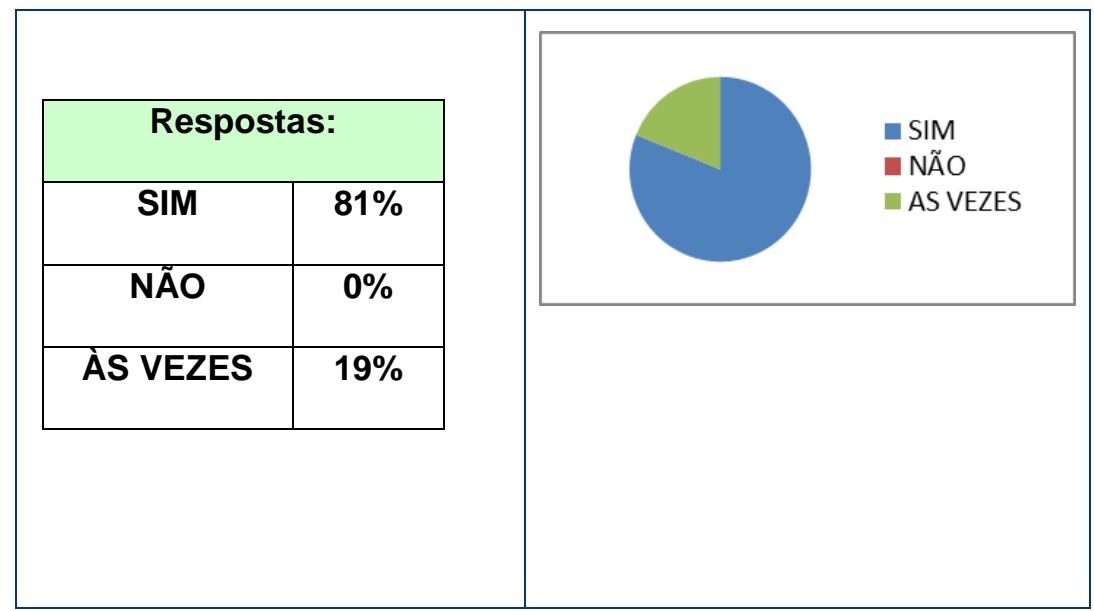

Fonte: Dados da pesquisa.

\section{C - Organização e armazenamento da informação}

O resultado da pesquisa mostra que a maioria das lideranças precisa buscar a informação, porque a mesma não está disponível como deveria. Essa constatação pode justificar-se pela dispersão das unidades da empresa e pode comprometer o processo de tomada de decisão. Mas, em contraponto, as lideranças afirmam manter um armazenamento de informações para consulta, o que permite concluir que talvez a forma de armazenamento não contribua para a busca rápida da informação, comprometendo a agilidade e o acesso. Segundo Choo (2006), "a maneira como a informação é armazenada reflete como a organização percebe e representa o seu ambiente" (CHOO, 2006, p. 417).

Diante dessa afirmação, ressalta-se a importância de manter a informação acessível e disponível, de forma a contribuir para que o seu ciclo de gestão se consolide e contribua para a eficácia dos processos de decisão.

\section{Gráfico 5}

Necessidade de buscar a informação em algum setor da Empresa, porque ela não chegou em tempo hábil

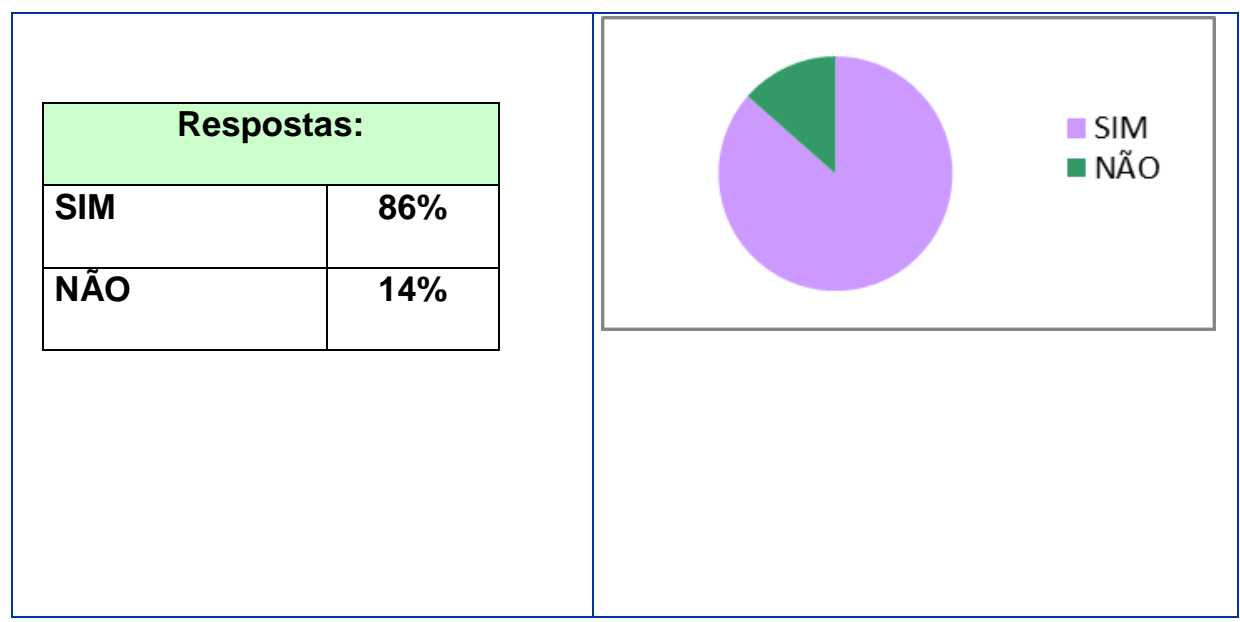

Fonte: Dados da pesquisa. 


\section{Gráfico 6}

\section{Arquivamento das informações recebidas ou transmitidas pelas lideranças aos seus subordinados para} posterior consulta ou comprovação

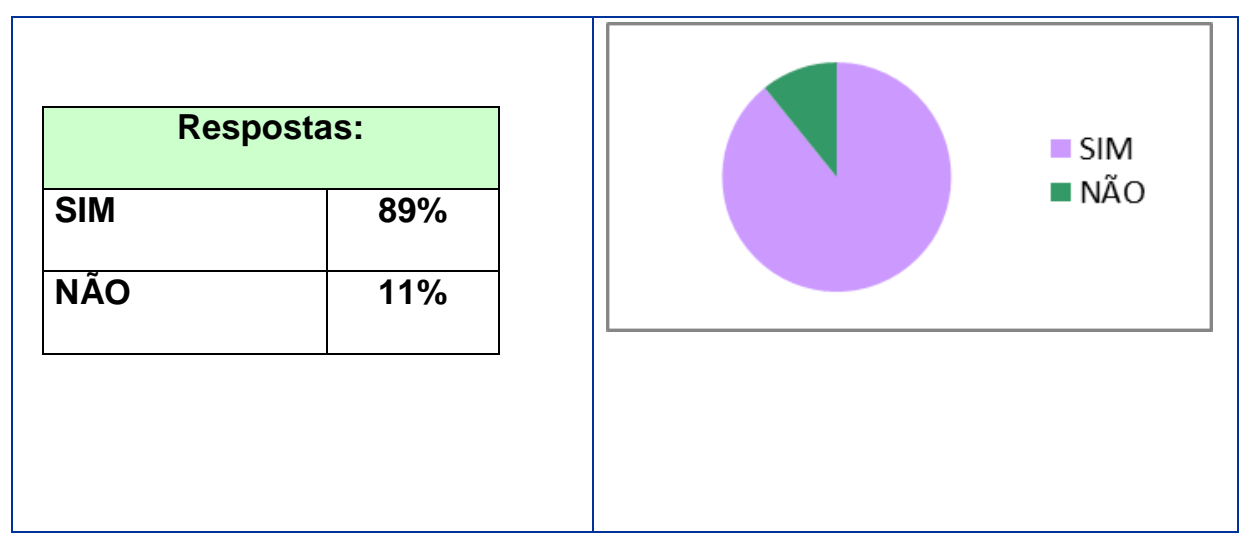

Fonte: Dados da pesquisa.

\section{D - Desenvolvimento de produtos e serviços de informação}

Para Choo (2006), o objetivo, ao desenvolver produtos e serviços de informação, deve atender não apenas à necessidade de informação do usuário, mas atender à sua necessidade de informação para o desenvolvimento de suas atividades.

A forma como a informação é disseminada, a periodicidade e a correta destinação da informação, na percepção dos envolvidos, são aspectos que precisam ser melhorados no fluxo de circulação da organização, o que permite inferir que a percepção da importância da informação é uma realidade organizacional, mas que há uma necessidade real de desenvolver produtos e serviços de informação que atendam aos gaps apresentados na pesquisa e, consequentemente, ao objetivo defendido pelo autor.

\section{Gráfico 7}

\section{O que pode melhorar no fluxo de informações na Empresa}

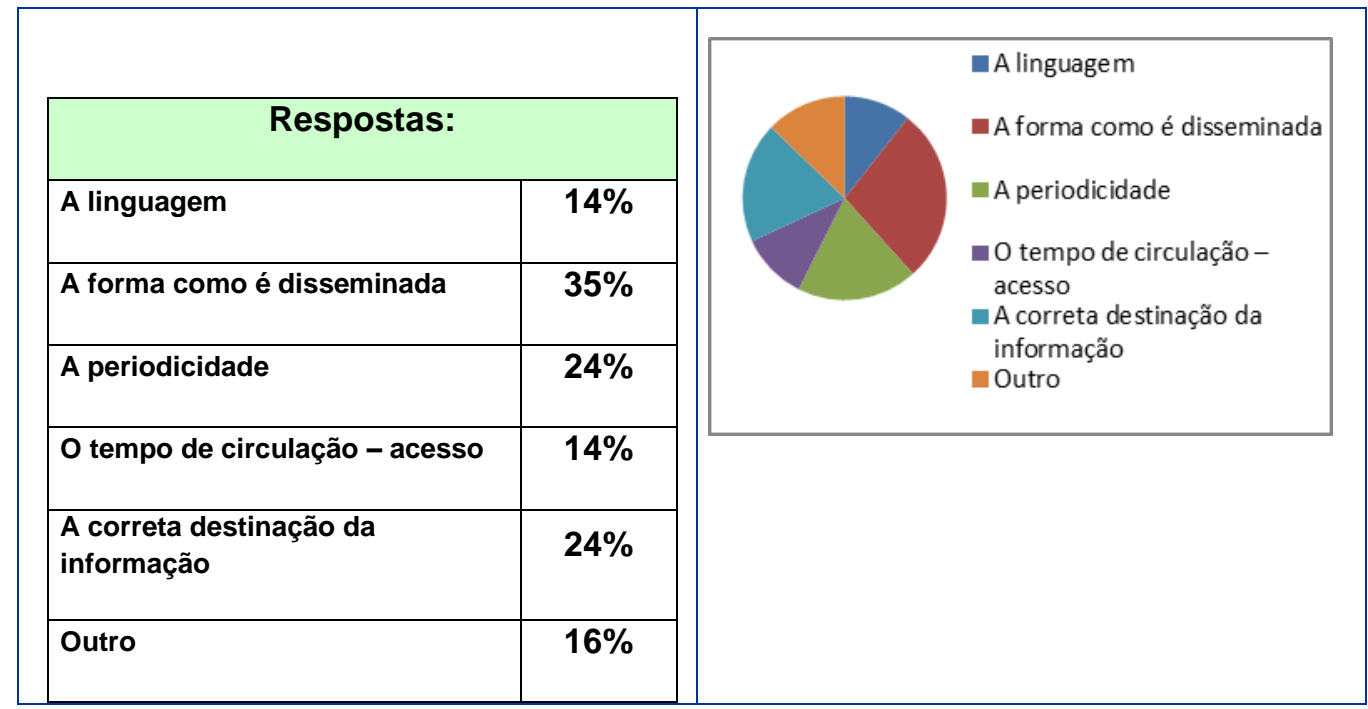

Fonte: Dados da pesquisa. 


\section{E - Distribuição da informação}

Verificou-se que $70 \%$ dos entrevistados compartilham as informações com os seus subordinados, o que permite afirmar que a distribuição da informação integra um conjunto de necessidades para que o fluxo ocorra em todos os processos, e que o ciclo de gestão da informação é relevante na organização. Outro aspecto relevante é o cuidado em transmitir a informação da mesma forma, visto que $65 \%$ dos entrevistados afirmam transmitir, enquanto $35 \%$ não, podendo ocorrer distorções no entendimento da informação e a suposição de que existe uma dificuldade em nivelar a informação, seja devido à dispersão dos públicos em todas as áreas da empresa ou pela característica de cada público, o que pode ser considerado como ponto de melhoria a ser trabalhado.

Esse resultado, associado à realidade de dispersão das unidades da empresa, reforça a importância de se considerar o que observa Choo (2006): "a entrega da informação deve ser feita por meios que estejam de acordo com os hábitos e preferências dos usuários de acordo com o seguinte princípio 'a informação certa para a pessoa certa, no formato local e horas certos"”. (CHOO, 2006, p. 414).

\section{Gráfico 8}

\section{Compartilhamento das informações que recebe da Empresa sobre os processos com os seus subordinados}

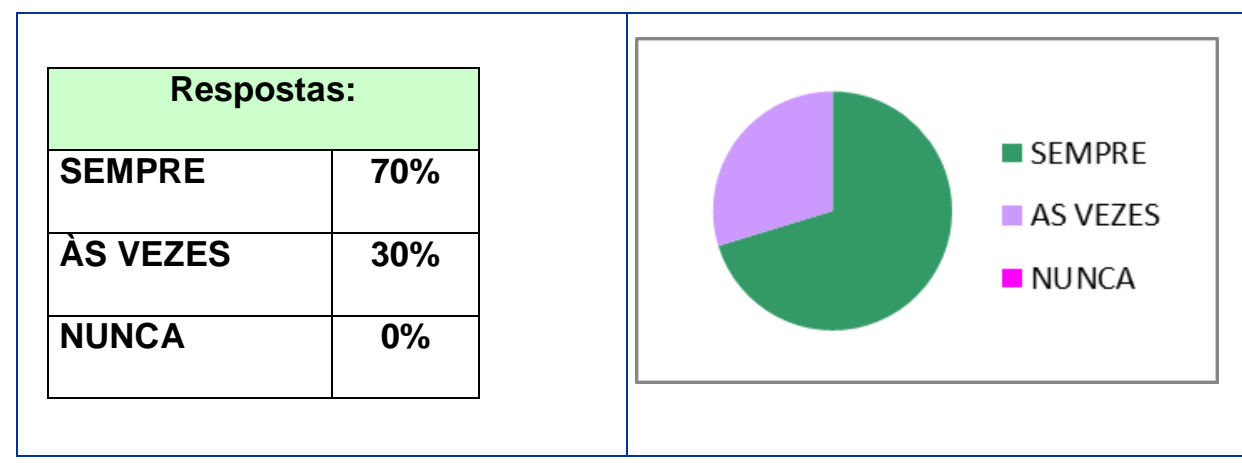

Fonte: dados da pesquisa.

Gráfico 9

Transmissão da informação da mesma forma a todos os subordinados

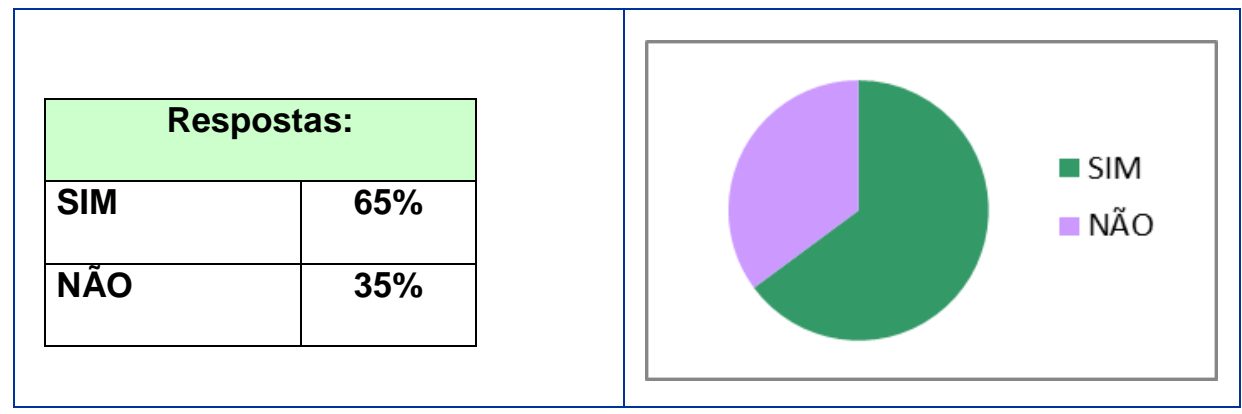

Fonte: dados da pesquisa. 


\section{F - Uso da informação}

A veracidade da informação é um fator que contribui para a percepção dos envolvidos e a relevância dela no dia a dia de suas atividades. Nesse contexto, a consulta à fonte é um mecanismo que minimiza distorções, mas que é pouco usual na organização em estudo. Apenas $49 \%$ dos entrevistados afirmaram geralmente consultar a fonte, enquanto $43 \%$ não consultam. Essa verificação leva à conclusão de que a veracidade da informação e sua relevância podem ficar comprometidas e comprometer também a clareza e a acessibilidade, percebidas apenas por $46 \%$ dos entrevistados. Outro aspecto identificado no uso da informação são as formas ou veículos de comunicação mais usuais, cujo destaque são para os diálogos com os colegas, seguido de reuniões e circulação de e-mails (via Outlook). O uso dessas ferramentas pode indicar uma necessidade latente por informação, a percepção de sua importância, mas é necessário ponderar que tais mecanismos também influenciam a veracidade. Se considerar que não estão armazenadas, acessíveis a todos, é passível de má interpretação, visto que os e-mails destinam-se à circulação rápida, sem muita complexidade ou aprofundamento do assunto, o que impacta também no item clareza e acessibilidade.

Dessa forma, o resultado da pesquisa sugere maior atenção com relação ao uso da informação, tanto pela realidade de dispersão das unidades da organização, o que "exige" maior "rigor" para garantir o acesso e a veracidade, quanto pela afirmação de Choo (2006) de que "o uso da informação envolve a seleção e o processamento da informação de modo a responder uma pergunta, resolver um problema, tomar uma decisão, negociar uma posição ou entender uma situação" (CHOO, 2006, p. 116).

\section{Gráfico 10}

\section{Consulta à fonte (o setor que encaminhou a informação) para confirmar a veracidade da informação antes de transmiti-la aos seus subordinados}

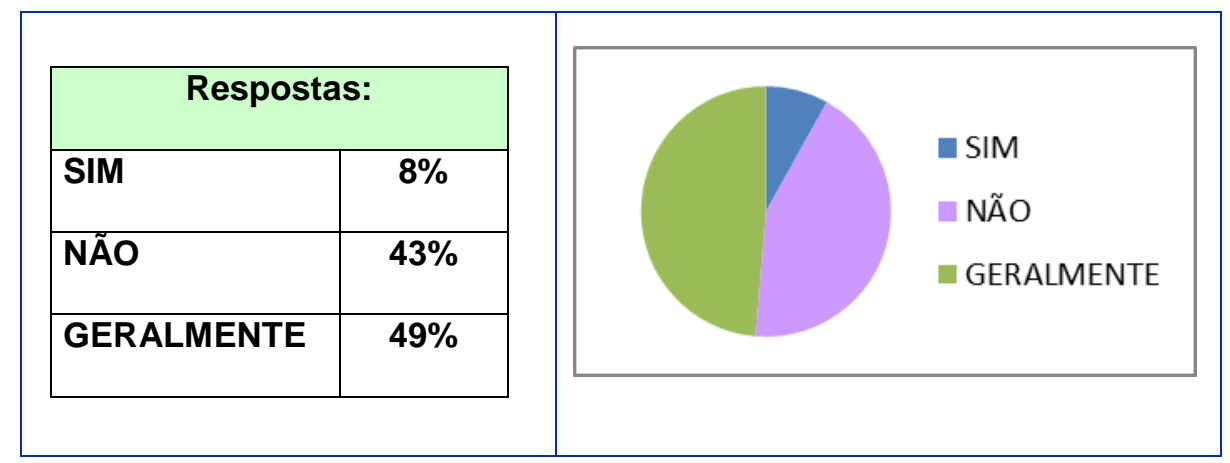

Fonte: dados da pesquisa.

Gráfico 11

Clareza e acessibilidade da informação que circula na Empresa

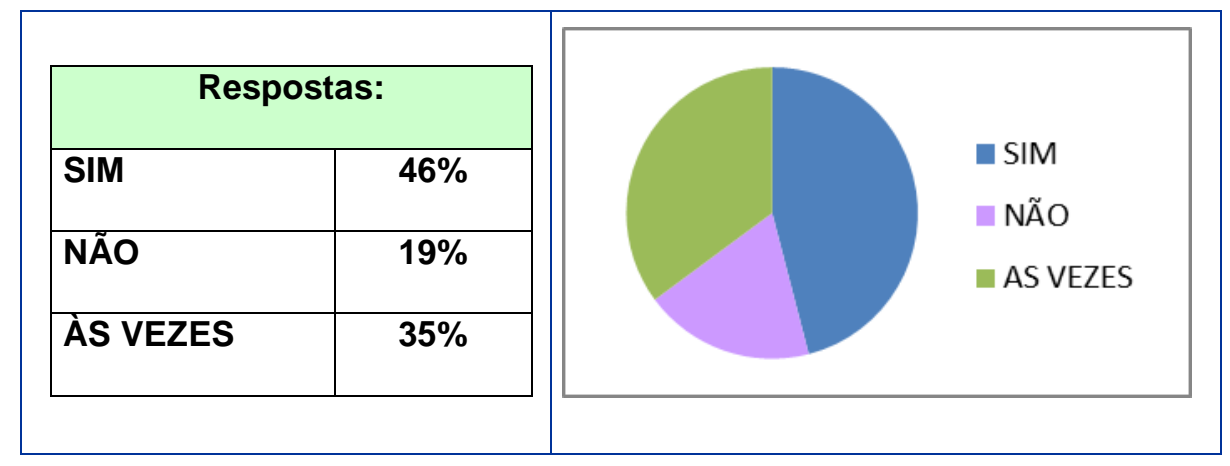

Fonte: Dados da pesquisa. 


\section{Gráfico 12}

\section{Veículos mais utilizados para transmissão da informação aos seus subordinados}

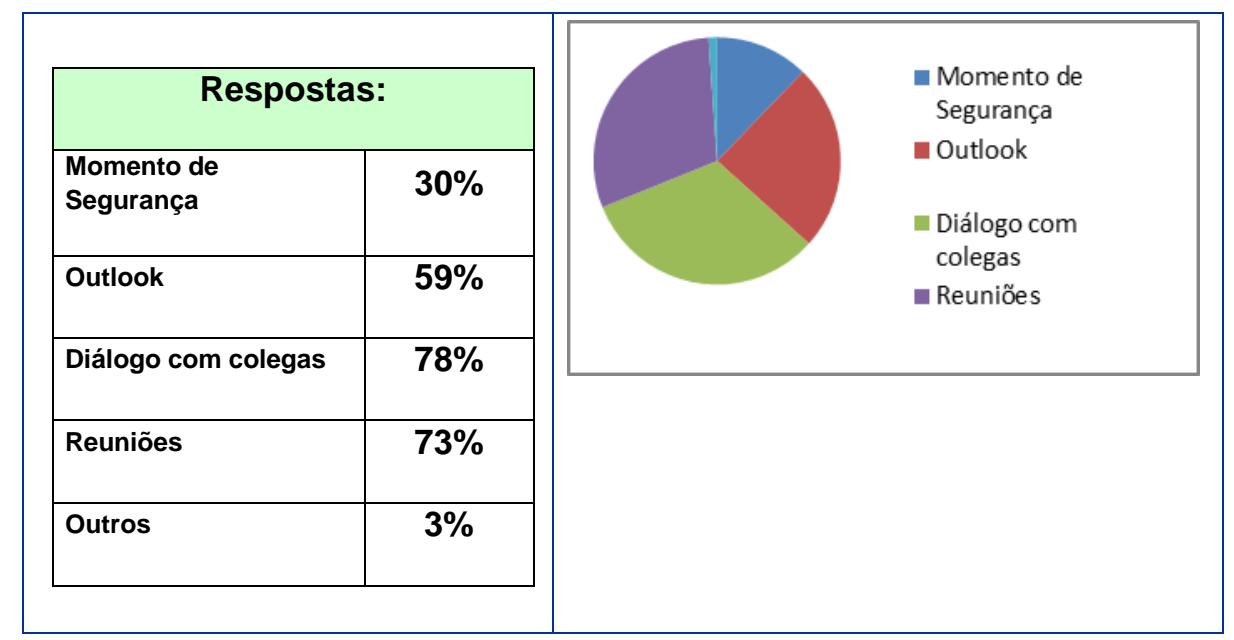

Fonte: Dados da pesquisa.

\section{Conclusão e Considerações Finais}

A percepção da informação e sua relevância no cenário institucional é um consenso na conclusão deste estudo. Ela contribui de forma significativa para o desenvolvimento das atividades da empresa e é percebida como item necessário no processo decisório. A circulação de informação na empresa é considerada importante por $100 \%$ dos entrevistados.

Tanto a aquisição quanto a disseminação da informação se revelam, neste estudo, como relevantes, embora se tenha identificado que, nem sempre, a informação está disponível para acesso rápido. $86 \%$ dos entrevistados afirmaram que precisam buscar a informação, pois não está disponível em tempo hábil. Foi identificado na pesquisa que, embora as lideranças da organização se preocupem em armazenar a informação para consulta, se necessário, existe um gap entre o armazenamento e o acesso, o que permite inferir que a forma de armazenamento é limitada; portanto, não contribui significativamente para a agilidade no processo de tomada de decisão. Se há uma necessidade de informação identificada pelos envolvidos, deveria haver maior disponibilidade da informação para atender às demandas por aquisição e disseminação.

Esse resultado aponta para um paradoxo entre a realidade identificada acima e a teoria estabelecida por Choo (2006), que afirma que "a maneira como a informação é armazenada reflete como a organização percebe e representa o seu ambiente" (CHOO, 2006, p. 417). Isso no tocante à necessidade de informação, considerada importante por unanimidade.

A forma como é disseminada e a correta destinação da informação é um ponto de melhoria mencionado no estudo, concluindo que os veículos adotados para uso da informação devem ser reavaliados, pois diálogos, reuniões e e-mails, apontados como as formas mais usuais, podem não suprir a necessidade de informação, de forma global, dentro da organização. Tal afirmação sugere o desenvolvimento de produtos e serviços de informação mais eficazes, conforme sugerido por Choo (2006), quando menciona que "a entrega da informação deve ser feita por meios que estejam de acordo com os hábitos e preferências dos usuários de acordo com o seguinte princípio 'a informação certa para a pessoa certa, no formato local e horas certos"”. (CHOO, 2006, p. 414). 
Outrossim, é possível inferir que a disseminação e a correta destinação são pontos de melhoria e que, possivelmente, o fator "dispersão" têm contribuído no reforço a esse gap, forçando a necessidade de criação e desenvolvimento do novos produtos e serviços de informação que atendam aos envolvidos no processo de tomada de decisão.

Quanto ao uso da informação, verificou-se que apenas $49 \%$ dos entrevistados afirmaram geralmente consultar a fonte, enquanto $43 \%$ afirmaram não consultar. Essa verificação leva à conclusão de que a veracidade da informação e sua relevância podem ficar comprometidas e comprometer também a clareza e a acessibilidade, percebidas apenas por $46 \%$ dos entrevistados quando questionados se a informação que circulava na organização era clara e acessível. Considerando a relevância da informação apresentada no cenário estudado, o uso da informação deve se estabelecer de forma mais criteriosa de modo a gerar veracidade e segurança no processo decisório, atendendo à afirmação de Choo (2006) de que "o uso da informação envolve a seleção e o processamento da informação de modo a responder uma pergunta, resolver um problema, tomar uma decisão, negociar uma posição ou entender uma situação" (CHOO, 2006, p. 116).

A conclusão deste estudo aponta uma significativa sinergia entre as respostas apresentadas, pois, ao cruzá-las com o ciclo de gestão da informação, sugerido por Choo (2003), e que embasa a realização deste trabalho, percebe-se que há uma clara "dependência" entre necessidade da informação, aquisição, desenvolvimento de produtos e serviços, armazenamento e uso da informação. A percepção da informação e de sua relevância no cenário organizacional está interligada ao ciclo de gestão da informação e, para que se efetive nessa organização, devem ser considerados todos os elementos que constituem o processo de comunicação nas organizações, conforme sugere Choo (2006), "a gestão da informação deve considerar o contexto social do uso da informação, uma vez que ela ganha significado e propósito pelo compartilhamento mental e afetivo" (CHOO, 2006, p. 416).

A gestão da informação e do conhecimento conduzem à construção de sentido, criação de conhecimento e tomada de decisão, elementos que se inter-relacionam com o ciclo de gestão da informação e faz com que ela seja processada com o propósito de reduzir ou evitar a incerteza e apoiar a tomada de decisão (CHOO, 2003).

Percebe-se, portanto, que a gestão da informação é bastante complexa e exige aprofundamento em elementos que complementem a sua compreensão e aplicabilidade. Este estudo contribui e sugere futuros avanços na mensuração do impacto e influência da informação e, mais ainda, a ampliação da percepção da importância da informação sob a perspectiva de colaboradores e subordinados da organização, a partir do qual se tornará possível o cruzamento de dados que possibilitará desenvolver um conceito global sobre a importância e relevância da informação no cenário organizacional sob a perspectiva de todos os envolvidos. 


\section{Referências}

BARBOSA, R. R. O uso de fontes de informação por consultores empresariais: um estudo junto ao mercado de consultoria de Belo Horizonte. Perspectivas em Ciência da Informação, Belo Horizonte, v. 13, n. 1, p. 95-101, jan./abr. 2007.

BARDIN. L. Análise de Conteúdo. Lisboa: Edições 70, 2002.

BARRETO, A. A. A eficiência Técnica e Econômica e a viabilidade de produtos e serviços de informação. Ciência da Informação, São Paulo, v. 25, n. 3, p. 1-18, jul. 1996. Disponível em: 〈http://revista.ibict.br/ciinf/index.php〉. Acesso em: 19 ago. 2011.

BATISTA, E. O. Sistema de Informação: o uso consciente da tecnologia para o gerenciamento. São Paulo: Saraiva, 2004.

CALAZANS, A. T. S. Conceitos e uso da informação organizacional e informação estratégica. Pesquisa Brasileira em Ciência da Informação e Biblioteconomia, v. 1, n. 2, 2006.

CHOO, C. W. The Knowing Organization: How Organizations Use Information for Construct Meaning, Create Knowledge and Make Decisions. Nova York: Oxford Press, 1998.

. A Organização do Conhecimento: como as organizações usam a informação para criar significado, construir conhecimento e tomar decisões. São Paulo: Editora Senac, 2003.

A Organização do Conhecimento: como as organizações usam a informação para criar significado, construir conhecimento e tomar decisões. São Paulo: Editora Senac, 2006.

DAVENPORT, T. H. Ecologia da Informação: por que só a tecnologia não basta para o sucesso na era da informação. São Paulo: Futura, 1998.

; PRUSAK, L. Conhecimento Empresarial: como as organizações gerenciam o seu capital intelectual. Rio de Janeiro: Campus, 1998.

GIL, A. C. Como elaborar projetos de pesquisa. 4. ed. São Paulo: Atlas, 2002.

LE COADIC, Y. A Ciência da Informação. Brasília: Briquet de Lemos, 2004.

MORESI, E. A. D. Delineando o valor do sistema de informação de uma organização. Ciência da Informação, Brasília, v. 29, n. 1, p. 14-24, jan./abr. 2000. Disponível em: 〈http://www.scielo.br/pdf/ci/v29n1/v29n1a2.pdf>. Acesso em: 12 set. 2011.

MORGAN, G. Imagens da Organização. São Paulo: Atlas, 1996.

NETO, R. D. C. A., Gestão do conhecimento em organizações. Curitiba: Saraiva, 2002.

OLIVEIRA, D. P. R. Sistemas de Informações Gerenciais: estratégias e táticas operacionais. 8. ed. São Paulo: Atlas, 1992.

TORQUATO, F. G. Comunicação Empresarial/Comunicação Institucional: conceitos, estratégias, sistemas, estrutura, planejamento e técnicas. 5. ed. São Paulo: Summus, 1986.

VERGarA, S. C. Projetos e Relatório de Pesquisa em Administração. 3. ed. São Paulo: Atlas, 2002.

WURMAN, R. S. Information Anxiety. The New York Times, New York, 1989. 32 p. 